\title{
The B chromosome system of Omocestus bolivari: changes in B-behaviour in $\mathbf{M}_{4}$-polysomic B-males
}

\author{
E. Viseras and \\ J. P. M. Camacho
}

Departamento de Genética, Facultad de Ciencias, Universidad de Granada, 18071 Granada, Spain.

\begin{abstract}
A metacentric B chromosome has been found in four out the five populations of Omocestus bolivari analysed. The B univalent frequently associates with the $X$ chromosome at prophase $I$. The iso-B nature is deduced from the persistent association between the two arms of the $B$, but it is neither confirmed nor denied by its $C$-banding response. At first meiotic division B univalents sometimes divide equationally which lead to their loss in the form of microspermatids. These aspects of meiotic behaviour of the iso-B's are significantly influenced by the $M_{4}$-polysomy.
\end{abstract}

\section{INTRODUCTION}

Many species of grasshopper carry supernumerary (B) chromosomes as extra elements in their cytogenetic systems (see Hewitt, 1979; Jones and Rees, 1982). These additional chromosomes are usually heterochromatic, show positively heteropycnotic at first meiotic prophase, and often associate with the $\mathrm{X}$ chromosome leading in some instances to a preferential migration of both elements to the same anaphase I pole (Smith, 1953; Henderson, 1961; Fontana and Vickery, 1973).

Omocestus bolivari is a grasshopper species endemic in the Sierra Nevada (Granada, Spain) in which extra chromosomes have been detected in the form of autosome polysomy and iso-B chromosomes (Camacho, 1980; Camacho et al., 1981). In the present report five natural populations of $O$. bolivari are analysed for B chromosome distribution and frequency, meiotic behaviour of the iso-B's and their elimination in the form of microspermatids.

\section{MATERIAL AND METHODS}

We caught $O$. bolivari specimens in five well separated populations representative of the distribution of this species: 40 males at Las Sabinas (LS, $2100 \mathrm{~m}$, North side of the Sierra Nevada), 18 males and 19 females at Campos de Otero (CO, $2200 \mathrm{~m}$, North side), 76 males at Albergue Universitario
(AU, $2500 \mathrm{~m}$, North side), 22 males at Alto del Chorrillo (ACH, $2700 \mathrm{~m}$, South side) and 55 males at La Alberquilla (LA, $2400 \mathrm{~m}$, South side).

Testes were fixed in $1: 3$ acetic ethanol. In the $\mathrm{CO}$ population testes and gastric caeca of each male were fixed following the method described by Kayano (1971). Females were injected with 0.05 per cent colchicine in insect saline solution for six hours before fixation of gastric caeca and ovarioles. All preparations for the routine cytogenetic analysis of the material were made by squashing in 2 per cent acetic orcein. Preparations for C-banding were made and treated following the technique described in Camacho and Cabrero (1983).

\section{RESULTS}

The medium sized metacentric B chromosome of $O$. bolivari is an iso-chromosome, as was reported by Camacho et al. (1981), on the basis of the similar length of its two arms and the meiotic pairing of them giving rise to ring $\mathrm{B}$ univalents (Camacho et al., 1981). We have further investigated this matter using the C-banding technique. Unfortunately, the $B$ chromosome shows only a minute paracentromeric C-band (fig. 1(a)). In consequence, since there are no interstitial $\mathrm{C}$-bands which could serve as chromosome markers, the C-banding pattern of the $\mathrm{B}$ chromosome neither confirms nor denies its iso-chromosome nature. 
The iso-B chromosome was found in four out of the five natural populations analysed. So, the frequency of males carrying it ranged among populations from $\mathrm{O}$ in $\mathrm{ACH}$ to 28 per cent in $\mathrm{CO}$ (table 1). One out of 19 females analysed from CO carried one iso- $\mathrm{B}$. In B-carrying males the iso- $\mathrm{B}$ chromosome was found in both the somatic (gastric caeca, fig. 1(e)) and germ lines (see fig. 1(a)), and its presence and number was constant in all cells in the carrier individuals which indicates it is a mitotically stable B chromosome.

Table 1 Frequency of the iso- $B$ in the populations

\begin{tabular}{lccc} 
& \multicolumn{3}{c}{ Male types } \\
Population & $\begin{array}{l}\text { B-carrier } \\
\text { males }\end{array}$ & $\%$ & $\begin{array}{l}\text { Standard } \\
\text { males }\end{array}$ \\
\hline LS & 3 & $7 \cdot 50$ & 37 \\
CO & 5 & 27.78 & 13 \\
AU & 7 & $9 \cdot 21$ & 61 \\
ACH & 0 & $0 \cdot 00$ & 22 \\
LA & 4 & $7 \cdot 27$ & 51 \\
\hline
\end{tabular}

* One male carried 2B's

We have analysed several aspects of meiotic behaviour of the iso-B's in B-carrying males and in two males from the AU population which were moreover mosaic for $\mathbf{M}_{4}$-polysomy viz., non homologous associations between $\mathrm{X}, \mathrm{B}$ and $\mathrm{M}_{4}$ (table 2), homologous association between the two arms of the iso-B (table 3), the formation of microspermatids and the frequency of equational division of the $B$ univalents during first meiotic division (table 4). Figs. I and 2 illustrate these aspects.

\section{DISCUSSION}

To date, we have not detected any accumulation mechanism of the iso- $\mathrm{B}$ on the male side but, on the contrary, a B-elimination seems to occur during spermatogenesis in the form of microspermatids. Why the $\mathrm{B}$ chromosomes of $O$. bolivari are maintained in the populations despite their elimination we do not know. The existence of an accumulation mechanism in females similar to those described in Myrmeleotetix maculatus (Hewitt, 1973; 1976) and Melanoplus femur-rubrum (Lucov and Nur, 1973) might explain it. However, in the $\mathrm{CO}$ population we found about 28 per cent of B-carrying males and only 5 per cent of Bcarrying females, so that although an accumulation mechanism existed in females it would not be very significant, given the low frequency of the $\mathrm{B}$ in them.
In some instances (like Myrmeleotettix maculatus) B-frequency variation among populations is correlated with environmental characteristics (Hewitt and John, 1967). In O. bolivari, although a more detailed transect is necessary, as far as the data go a correlation seems to exist between Bfrequency and altitude. So, in the highest population analysed (ACH, $2700 \mathrm{~m}$ ) we have not found $\mathrm{B}$ chromosomes. The major B-frequency observed is that of CO $(2200 \mathrm{~m})$, one of the lower populations sampled. Intermediate altititudes have intermediate B-frequencies. The substantial difference, besides temperature, between higher and lower populations is that in the former the snow covers the ground for more time each year and, consequently, in them the period for grasshopper development, fertilisation and laying is shorter than in lower populations. So, in higher populations genotypes which more quickly complete their life-cycle will be favoured by natural selection. It has been demonstrated that B chromosomes of the grasshopper Myrmeleotettix maculatus slow development (Harvey and Hewitt, 1979). Significantly, in our highest population ( $\mathrm{ACH}$ ) individuals with extra chromosomes were not found, neither $\mathrm{B}$ chromosomes (this paper) nor polysomic $\mathrm{M}_{4}$ autosomes (Viseras and Camacho, 1984), which indicates that zygotes carrying extra chromosomes may have reduced fitness in this environment. In lower populations there is snow for less time and any developmental retardation produced by extra chromosomes $\left(\mathrm{B}\right.$ or $\mathrm{M}_{4}$ ) is less crucial for survival of the individuals, as indicated by the presence in the AU population of two males carrying simultaneously $\mathrm{B}$ and extra $\mathrm{M}_{4}$ chromosomes.

An interesting result is the influence of $\mathbf{M}_{4}$ polysomy on meiotic B-behaviour. Two B-carrying males from the AU population were also mosaic for $\mathbf{M}_{4}$-polysomy, which is characterised by the presence in some cells of heterochromatinised $\mathrm{M}_{4}$ chromosomes (het- $\mathrm{M}_{4}$ 's). In these males the $\mathrm{B}$ takes part in heterochromatic non-homologous associations (with the $\mathrm{X}$ and the het- $\mathrm{M}_{4}$ ) at a lower frequency than in non polysomic B-males. Also the two homologous arms of the iso- $B$ pair much more frequently in $\mathbf{M}_{4}$-polysomic $\mathbf{B}$-males than in B-males. A similar correspondence between the levels of homologous and non homologous associations is apparent for het- $\mathrm{M}_{4}$ chromosomes. In this case, cells with 2 het- $M_{4}$ 's show higher homologous pairing along with lower non homologous association than cells carrying a single het- $\mathbf{M}_{4}$. Another change in meiotic $\mathrm{B}$-behaviour in $\mathbf{M}_{4}$-polysomic $\mathrm{B}$-males is their increased frequency of equational 

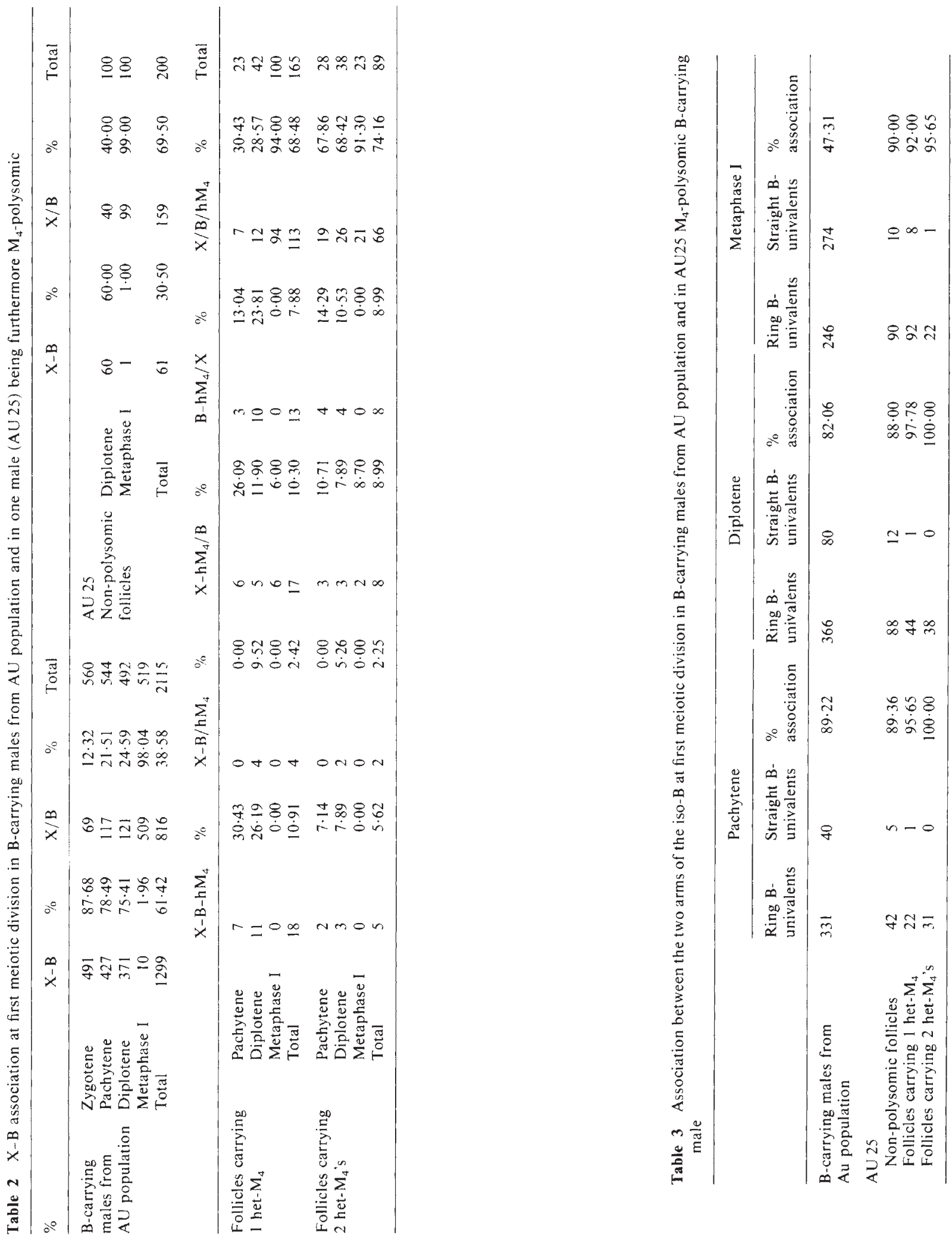


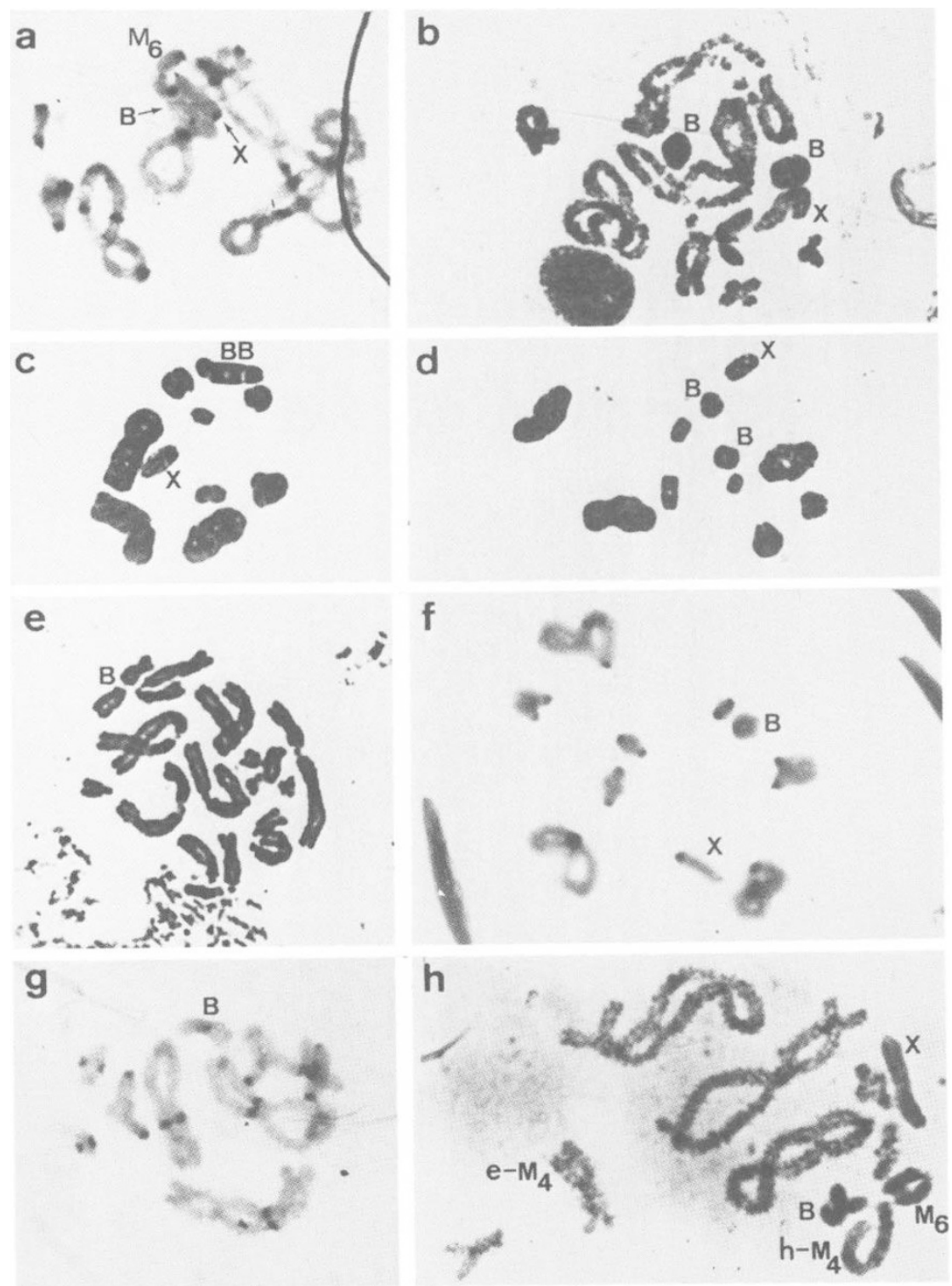

Figure 1. B chromosomes of Omocestus bolivari. (a) (-banded diplotene cell showing non-specific associations between $\mathrm{X}$, B and $\mathrm{M}_{\mathrm{f}}$ chromosomes. Observe that the straight $\mathrm{B}$ chromosome shows a single minute paracentromeric $\mathrm{C}$-band. (b-d) $O$ rcein stained primary spermatocytes from a $2 \mathrm{~B}$ male showing two ring B-univalcnts (b and d) and onc B-bivalent (c). (c) Mitotic metaphase plate of gastric caeca from a B-male. (f and $g$ ) (-banded primary spermatocytes showing ring B-univalent (f) and straight B-univalent $(\mathrm{g})$. (h) Diplotene cell showing the B positively heteropycnotic with an interstitial chiasma. This cell also contains an extra heterochromatic $M_{4}$-bivalent $\left(h-M_{4}\right)$ differentially stained of the euchromatic $M_{4}$-bivalent $\left(e-M_{4}\right)$. 


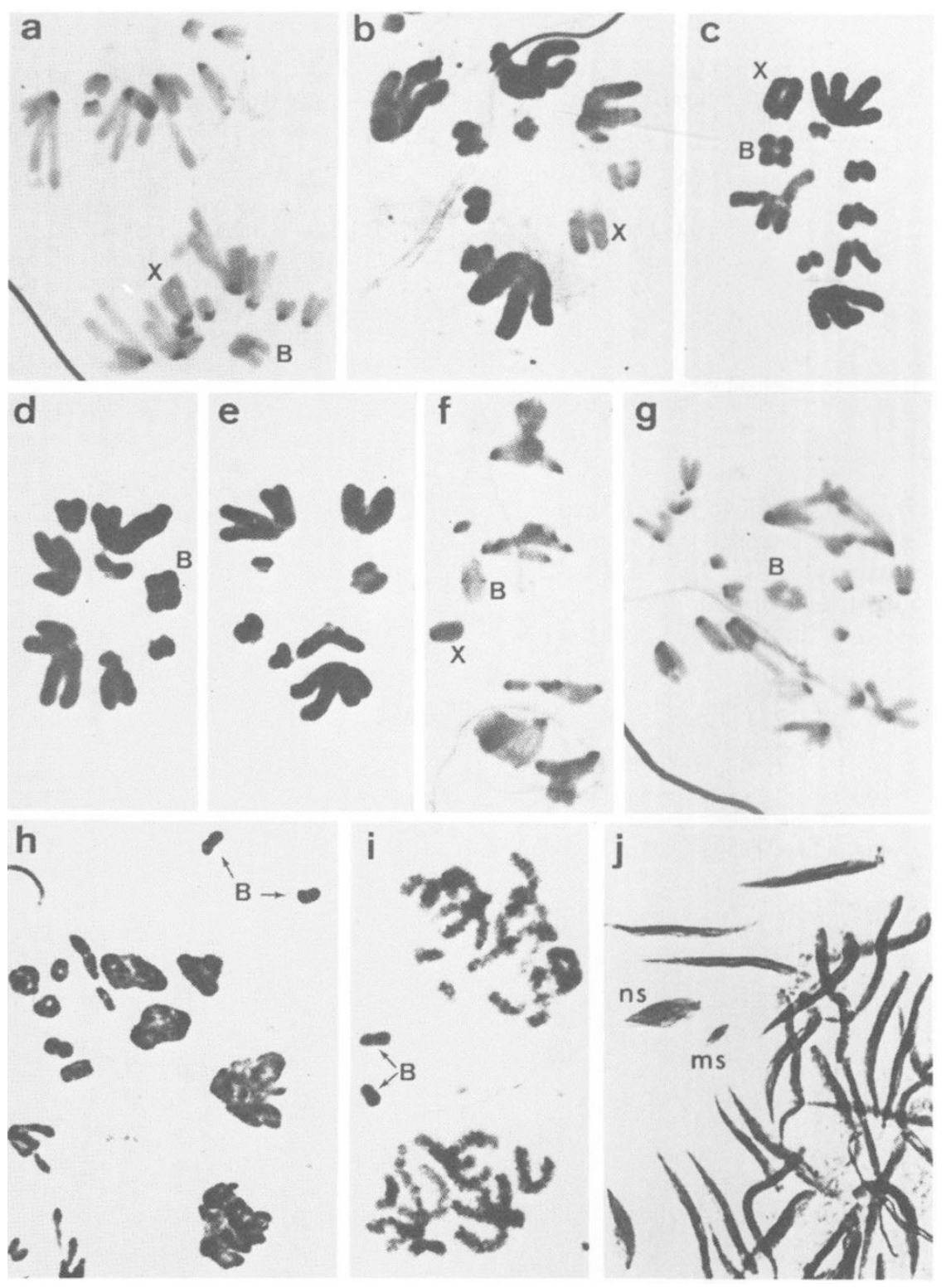

Figure 2. B chromosomes of $O$. bolivari during the first meiotic division and formation of inicrospermatids. (a) Anaphase $I$ cell showing reductional division of the B-univalent. (b-e) Metaphase II cells derived from reductional divisions, showing $n=8+X$ (b), $n=8+X+B$ (c), $n=8+B$ (d) and $n=8$ chromosomes (e). (f and g) Late metaphase I (f) and early anaphase I (g) cells showing equational division of the B-univalent. $(\mathrm{h}-\mathrm{j})$ The hemi-B chromosomes arisen from equational division which lay far from the rest of the chromosomes ( $h$ and $i)$ may get lost in the form of microspermatids (j). Compare in (j) the size of the normal haploid spermatids (ns) with the microspermatids (ms). 
Table 4 Frequency of equational division of the $B$ univalents (B eq) and frequency of microspermatids $(\mathrm{ms})$ in different types of males from LA and AU populations

\begin{tabular}{|c|c|c|c|c|}
\hline \multirow[b]{2}{*}{ Male type } & \multicolumn{2}{|c|}{ Equational division } & \multicolumn{2}{|c|}{ Microspermatids } \\
\hline & $\begin{array}{l}\text { Total } \\
\text { metaphase } \\
\text { II cells } \\
\text { analysed }\end{array}$ & $\% \mathrm{~B} \mathrm{eq}$ & $\begin{array}{l}\text { Total } \\
\text { spermatids } \\
\text { analysed }\end{array}$ & $\% \mathrm{~ms}$ \\
\hline $\begin{array}{l}\text { Standard } \\
\text { LA males }\end{array}$ & & & 1436 & 0.00 \\
\hline $\begin{array}{l}\text { B-carrying } \\
\text { LA males }\end{array}$ & 110 & $8 \cdot 18$ & 1634 & 0.73 \\
\hline $\begin{array}{l}\text { Standard } \\
\text { AU males }\end{array}$ & & & 3088 & $0 \cdot 16$ \\
\hline $\begin{array}{l}\text { B-carrying } \\
\text { AU males }\end{array}$ & 637 & $21 \cdot 66$ & 1208 & $2 \cdot 07$ \\
\hline $\begin{array}{l}\mathrm{M}_{4} \text {-polysomic } \\
\text { B-carrying } \\
\text { AU males }\end{array}$ & 71 & $77 \cdot 50$ & 1437 & $3 \cdot 69$ \\
\hline
\end{tabular}

division during first meiotic divisions with respect to B-males. This is accompanied by an increased frequency of microspermatids. The additional microspermatids might be formed by the extra equationally divided and lagging B's and also by the het-M ${ }_{4}$ 's.

\section{REFERENCES}

CAMACHO, J. P. M. 1980. Variabilidad cromosómica en poblaciones naturales de Tettigonioidea, Pamphagoidea y Acridoidea. Tesis Doctoral, Fac. Ciencias, Univ. Granada, Spain.
CAMACHO, J. P. M. AND CABRERO, J. 1983. Karyological differences between two species of grasshopper genus Acrotylus (Acrididae: Oedipodinae). Caryologia, 36, 121-127.

CAMACHO, J. P. M., DIAZ DE LA GUARDIA, R. AND RUIZ REJON, M. 1981. Polysomy and supernumerary isochromosomes in the grasshopper Omocestus bolivari (Chopard). Heredity, 46, 123-126.

FONTANA, P. G. AND VICKERY, V. R. 1973. Segregation-distortion in the B-chromosome system of Tettigidea lateralis (Say) (Orthoptera: Tetrigidae). Chromosoma, 43, 75-100.

HARVEY, A. W. AND HEWITT, G. M. 1979, B-chromosomes slow development in a grasshopper. Heredity, 42, 397-401.

HENDERSON, S. A. 1961. The chromosomes of the British Tetrigidae (Orthoptera). Chromosoma, 12, 553-572.

HEWITT, G. M. 1973. Variable transmission rates of a B-chromosome in Myrmeleotettix maculatus (Thunb) (Acrididae: Orthoptera). Chromosoma, 40, 83-106.

HEWITT, (i. M. 1976. Meiotic drive for B-chromosomes in the primary oocytes of Myrmeleotettix maculatus (Orthoptera: Acrididae). Chromosoma, 56, 381-391.

HEWITT. (;. M. 1979. Grasshoppers and Crickets. Animal Cytogenetics. Vol. 3, Insecta 1, Orthoptera. Gebrüder Borntraeger, Berlin-Stuttgart

HEWITT, G. M. AND JOHN, B. 1967. The B-chromosome system of Myrmeleotettix maculatus (Thunb) 111. The statistics. Chromosoma, 21, 140-162.

JONES. R. N. AN1) REES, H. 1982. B Chromosomes. Academic Press Inc., London.

KAYAN(), H. 1971. Accumulation of B chromosomes in the germ line of Locusta migratoria. Heredity, 27, 119-123.

LUCOV.Z. ANI) NUR, U. 1973. Accumulation of B chromosomes by preferential segregation in females of the grasshopper Melanoplus femur-rubrum. Chromosoma, 42, 289-306.

SMITH, S. G. 1953. A pseudo-multiple sex-chromosome mechanism in an Indian gryllid. Chromosoma, 5, 555-573.

VISERAS, F. ANI) CAMACH(), J. P. M. 1984. Polysomy in Omocestus bolivari: Endophenotypic effects and suppression of Nucleolar Organizing Region activity in the extra autosomes. Can. J. Genet. Cytol., 26, 547-556. 